\title{
EARTHQUAKE-INDUCED DAMAGE TO EARTH STRUCTURES AND PROPOSAL FOR REVISION OF THEIR DESIGN POLICY-BASED ON A CASE HISTORY OF THE 2011 OFF THE PACIFIC COAST OF TOHOKU EARTHQUAKE-
}

\author{
Fumio TATSUOKA ${ }^{1}$, Junichi KOSEKI ${ }^{2}$ and Akihiro TAKAHASHI ${ }^{3}$ \\ ${ }^{1}$ Member of JSCE, Professor, Dept. of Civil Eng., Tokyo University of Science \\ (2641, Yamazaki, Noda-shi, Chiba 278-8510, Japan) \\ E-mail: tatsuoka@rs.noda.tus.ac.jp \\ ${ }^{2}$ Member of JSCE, Professor, Dept. of Civil Eng., the University of Tokyo \\ (7-3-1, Hongo, Bunkyo-ku, Tokyo 113-8656, Japan) \\ E-mail: koseki@civil.t.u-tokyo.ac.jp \\ ${ }^{3}$ Member of JSCE, Professor, Dept. of Civil \& Environmental Eng., Tokyo Institute of Technology \\ (2-12-1, O-okayama, Meguro-ku, Tokyo 152-8552, Japan) \\ E-mail: takihiro@cv.titech.ac.jp
}

\begin{abstract}
During the 2011 Off the Pacific Coast of Tohoku Earthquake, a great number of earth structures suffered widespread damage. It took a significantly long time to repair, restore, or reconstruct many of them, and thus the relief operation activities and the rehabilitation works to be conducted at the sites and in the nearby areas were severely obstructed owing to the loss of their function.

In this paper, a severe collapse case history of earth-fill dams for an irrigation reservoir is described as a typical and representative case. Based on the lessons learned, a proposal is made for the revision of their design policy, particularly in terms of soil compaction control and issues related to seismic design and construction of earth structures to satisfy the required seismic performance. Its application to the restoration works of the collapsed earth-fill dams is also preliminary reported.

It is shown that the old dams collapsed due mainly to their generally poor compacted state and because their top fill consisted of particularly poor compacted sandy soil. The relevant and realistic design should be based on the following procedures: a) use of Level 2 design seismic load relevant to a given earth structure; b) use of realistic soil shear strength, corresponding to the average of actual values of the degree of compaction, which is noticeably higher than the given allowable lower bound; and c) evaluation of the stability by comparing the calculated residual displacement/deformation of a given earth structure with the allowable limit specified in the design. The results of the compaction control at the early stage of the restoration work for the new dams show that the newly proposed method that controls the water content of the backfill to be compacted and the dry density and the degree of saturation of compacted soil works very well.
\end{abstract}

Key Words: the 2011 Off the Pacific Coast of Tohoku Earthquake, earth structures, case history, earth-fill dams, seismic design policy, compaction control, restoration work

\section{INTRODUCTION}

During the 2011 Off the Pacific Coast of Tohoku Earthquake (or the East Japan Great Earthquake Disaster), a great number of earth structures, such as earth-fill dams, embankments, and soil retaining walls, suffered widespread damage, as summarized in the damage survey report compiled by the Joint Editorial Committee for the Report on the Great East
Japan Earthquake Disaster (2015) ${ }^{1)}$.

Many of the case histories on damage to earth structures, as well as the relevant design policies that were effective at the time of the earthquake, were also collected and analyzed by a research committee established by the Japanese Geotechnical Society (JGS) to investigate aseismic measures for earth structures ${ }^{2)}$.

Tables 1 through Table 4 summarize the existing 
seismic design policies of railway earth structures, highway earth structures, river dikes, and earth-fill dams for irrigation reservoir, respectively, in Japan that were effective at the time of the 2011 earthquake. Against the so-called "Level 2" design earthquake load, which is as severe as the one experienced during the 1995 Hyogoken-Nanbu (or Kobe) Earthquake, no seismic design has been specified, except for important railway and highway earth structures as well as river dykes for which limited extent of damage is allowed as far as their functions can be restored by quick repair works. Such policies are generally based on the assumption that earth structures are relatively easy to repair, compared to other types of structures.

The aforementioned surveys and analyses, however, revealed that it took a significantly long time to repair, restore, or reconstruct many of the damaged earth structures, and thus the relief operation activities and the rehabilitation works to be conducted at the sites and in the nearby areas were severely obstructed owing to the loss of their functions.

In view of the above, Chapter 2 of this paper describes a severe collapse case history of earth-fill dams for an irrigation reservoir, which was induced by the 2011 Off the Pacific Coast of Tohoku Earthquake, as a typical one that illustrates the need for a relevant revision of conventional seismic design policy and construction practice. Based on the lessons learned, a proposal to revise their design policy is made in Chapter 3, particularly in terms of soil compaction control and issues related to seismic design and construction of earth structures to satisfy the required seismic performance. Consequently, its application to the restoration works of the collapsed earth-fill dams is preliminary reported in Chapter 4, followed by a summary in Chapter 5 .

\section{COLLAPSE OF FUJINUMA DAMS}

\section{(1) Outline}

Fujinuma agricultural irrigation reservoir was located in Sukagawa City, Fukushima Prefecture and had main and auxiliary dams. The construction of these dams started in April 1937, suspended during World War II, and completed in October 1949. The main dam (Fig. 1) was an earth-fill dam with a height of $18.5 \mathrm{~m}$ and crest length of $133.2 \mathrm{~m}$ (Fig. 2 and Table 5). The old main dam had no central core zone. The auxiliary dam was also an earth-fill dam with a height of $10.5 \mathrm{~m}$ and a crest length of $72.5 \mathrm{~m}$. During a period from 1977 to 1979 , the spillway and surface protection work of the main dam were repaired and, for a period from 1984 to 1992, countermeasures
Table 1 Seismic design policies of railway earth structures in Japan (modified after JGS, 2014) ${ }^{2)}$.

\begin{tabular}{|c|c|c|}
\hline $\begin{array}{l}\text { Design EQ loads } \\
\text { Importance } \\
\text { of structures }\end{array}$ & $\frac{\text { Level 1: }}{\text { Conventional }{ }^{11}}$ & $\begin{array}{l}\text { Level 2: } \\
\text { Severe as experienced during } \\
\text { the } 1995 \text { Kobe } \mathrm{EQ}^{2}\end{array}$ \\
\hline $\begin{array}{l}\text { Very important: } e . g ., \\
\text { high speed trains (rank } \\
\text { I) }\end{array}$ & \multirow{2}{*}{$\begin{array}{l}\text { Limited deformation. } \\
\text { No repair works are } \\
\text { needed to maintain } \\
\text { the service }\end{array}$} & $\begin{array}{l}\text { Allowed to exhibit deformation } \\
\text { as far as their functions can be } \\
\text { restored by quick repair works }\end{array}$ \\
\hline $\begin{array}{l}\text { Important: e.g., urban } \\
\text { trains (rank II) }\end{array}$ & & $\begin{array}{l}\text { Should not exhibit devastating } \\
\text { deformation. The functions can } \\
\text { be restored by repair works }\end{array}$ \\
\hline Others (rank III) & Should not collapse & Not specified \\
\hline
\end{tabular}

1) Anticipated to take place at a given site several times during the design life time.

2) The largest seismic load anticipated at a given site during the design life time.

Table 2 Seismic design policies of highway earth structures in Japan (modified after JGS, 2014) ${ }^{2)}$.

\begin{tabular}{|l|l|l|}
\hline $\begin{array}{l}\text { Resign EQ loads } \\
\text { Importance } \\
\text { of structures }\end{array}$ & $\begin{array}{l}\text { Level 1: } \\
\text { highly expected over the } \\
\text { design life time, } \mathrm{T}_{\text {des }}\end{array}$ & $\begin{array}{l}\text { Level 2: } \\
\text { possibly maximum over } \\
\mathrm{T}_{\text {des }}\end{array}$ \\
\hline $\begin{array}{l}\text { Very important: } \text { e.g., in } \\
\text { case of failure, sever } \\
\text { effects on traffic } \\
\text { functions and nearby } \\
\text { facilities (rank I) }\end{array}$ & $\begin{array}{l}\text { Should not lose structural } \\
\text { soundness }\end{array}$ & $\begin{array}{l}\text { Allowed to undergo limited } \\
\text { damage as far as their } \\
\text { functions can be restored } \\
\text { by quick repair works }\end{array}$ \\
\hline Others (rank II) & $\begin{array}{l}\text { Allowed to undergo limited } \\
\text { damage as far as their } \\
\text { functions can be restored } \\
\text { by quick repair works }\end{array}$ & $\begin{array}{l}\text { Should not exhibit fatal } \\
\text { damage }\end{array}$ \\
\hline
\end{tabular}

Table 3 Seismic design policies of river dykes in Japan (modified after JGS, 2014) $^{2)}$.

\begin{tabular}{|l|l|l|}
\hline $\begin{array}{l}\text { Type } \\
\text { of structures }\end{array}$ & Level 2: \\
\hline $\begin{array}{l}\text { Conventional earthen } \\
\text { levees (with inland } \\
\text { elevation lower than } \\
\text { river water level) }\end{array}$ & Not specified & $\begin{array}{l}\text { Should maintain the } \\
\text { levee function not to } \\
\text { allow overflow of } \\
\text { river water }\end{array}$ \\
$\begin{array}{l}\text { Self-supported walls } \\
\text { (with inland elevation } \\
\text { lower than river water } \\
\text { level) }\end{array}$ & $\begin{array}{l}\text { Should not lose structural } \\
\text { soundness (reinforced concrete } \\
\text { walls), or not specified (sheet } \\
\text { pile walls) }\end{array}$ & \\
\hline
\end{tabular}

Table 4 Seismic design policies of earth-fill dams for irrigation reservoir in Japan (modified after JGS, 2014) ${ }^{2}$.

\begin{tabular}{|c|c|c|}
\hline $\begin{array}{l}\text { Design EQ loads } \\
\text { Importance } \\
\text { of structures }\end{array}$ & Level 1: & Level 2: \\
\hline $\begin{array}{l}\text { Very important: e.g., } \\
\text { sever effects on nearby } \\
\text { facilities and local } \\
\text { activities (type A) }\end{array}$ & $\begin{array}{l}\text { Should not lose structural } \\
\text { soundness (or undergo yielding), } \\
\text { even against possible liquefaction }\end{array}$ & \multirow{2}{*}{$\begin{array}{l}\text { Not specified* } \\
\text { ("under revision } \\
\text { after the } 2011 \text { Off } \\
\text { the Pacific Coast } \\
\text { of Tohoku } \\
\text { Earthquake) }\end{array}$} \\
\hline $\begin{array}{l}\text { Important: e.g., large } \\
\text { effects in case of } \\
\text { failure (type B) }\end{array}$ & $\begin{array}{l}\text { Should not lose structural } \\
\text { soundness (or undergo yielding), } \\
\text { while not considering liquefaction }\end{array}$ & \\
\hline Othe & & \\
\hline
\end{tabular}
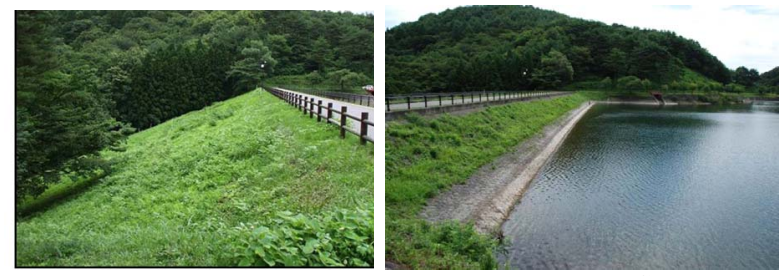

Fig. 1 Views of old main Fujinuma dam³). 
against leakage by grouting and upgrading of intakes were conducted. The agricultural water taken from Fujinuma Reservoir irrigates 837 ha of land and the dam had been managed and operated by the Ebanagawa Irrigation District.

Both main and auxiliary dams totally collapsed during the 2011 Off the Pacific Coast of Tohoku Earthquake. A large amount of impounded water released by the breach of the main dam (Fig. 3) reached the downstream community causing the loss of seven lives and one person missing. As a result of the earthquake, roughly 750 of other small irrigation dams were damaged in the Fukushima Prefecture alone. Tanaka et al. ${ }^{3)}$ reported that the old main dam collapsed due mainly to: 1) the generally poor compacted state of the whole dam; 2) the particularly poor compacted sandy soil used for the top fill, which was highly susceptible to a significant reduction of undrained strength during seismic loading while highly erodible when subjected to overtopping flow; and 3 ) the strong and prolonged seismic motion. New fill dams that are much more stable than the old ones are under construction to be completed by April 2017.

\section{(2) Collapse mechanism}

Figure 3 was taken around PM 15:11, 11 March 2011, while the main shock of the earthquake started at 14:46. Therefore, it was very likely that the collapse started during the earthquake. The fact that part of the upstream side of the middle fill survived (Fig. 3) while the top fill was totally lost indicates that the soil type of the top fill was much more erodible than the middle fill. Figures $4 \mathrm{a}$ and $\mathbf{4 b}$ show the inferred collapse mechanism of the old main dam. The numbers shown in Fig. 4a indicate the sequence of occurrence of sliding. Although only a single slide 1 is depicted in Figs. 4a and 4b, it is likely that multiple slides 1 took place progressively, which might have resulted in the loss of the whole cross-section of the top fill somewhere along the crest length which, in turn, might have facilitated the start of the overtopping flow. It is certain that this overtopping flow quickly eroded the top fill, which resulted in the breaching of the dam.

The typical grading curves and the results of laboratory compaction tests using the materials retrieved from the zones that survived the earthquake, together with the results of soil dry density and water content measurements in the field, are presented in Figs. 5a and 5b. The compaction energy level was Standard Proctor (1Ec) in the most compaction tests, while Modified Proctor (4.5Ec) was used only with the top fill material. The backfill material of the top fill, which was constructed after World War II a)

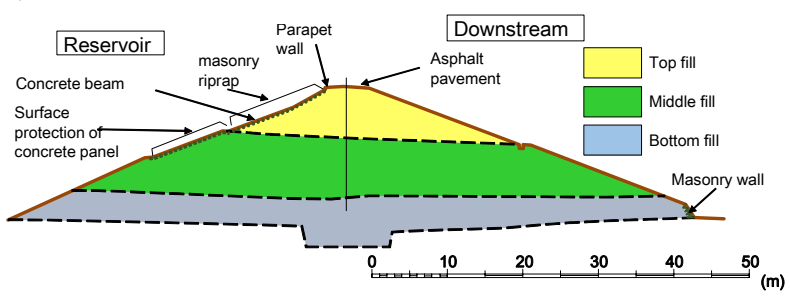

b)

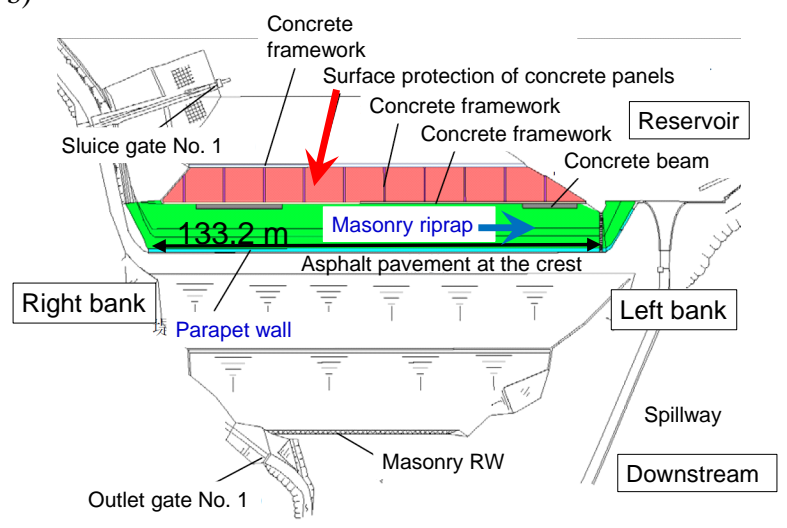

Fig. 2 a) Typical cross-section; and b) plan of main Fujinuma $\mathrm{dam}^{3)}$.

Table 5 Outline of old Fujinuma dams.

\begin{tabular}{|c|c|}
\hline Commissioning Entity & Fukushima Prefecture \\
\hline Location & Sukagawa City, Fukushima Prefecture \\
\hline Purpose & $\begin{array}{c}\text { Main dam: earth-fill dam } \\
\text { Auxiliary dam: earth-fill Dam }\end{array}$ \\
\hline Type & Main : $18.5 \mathrm{~m}$ Auxiliary : $10.5 \mathrm{~m}$ \\
\hline Height & Main : $133.2 \mathrm{~m}$ Auxiliary $: 72.5 \mathrm{~m}$ \\
\hline Crest length & Main : $99,000 \mathrm{~m}^{3}$ \\
\hline Volume & $1,500,000 \mathrm{~m}^{3}$ \\
\hline Total storage capacity & $1,480,000 \mathrm{~m}^{3}$ \\
\hline Effective storage capacity & 1949 \\
\hline Completed & \\
\hline
\end{tabular}

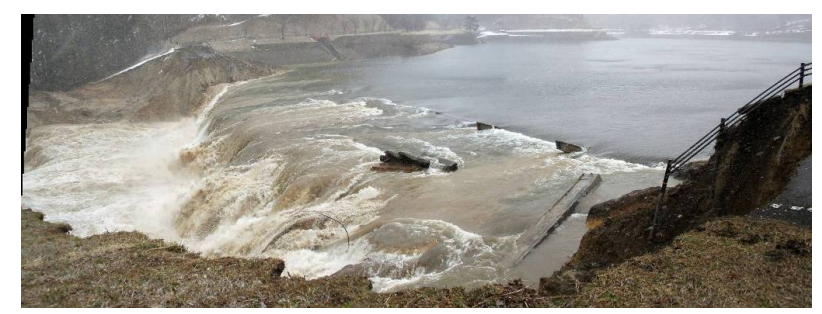

Fig. 3 Breaching state of main Fujinuma dam (taken around PM 15:11, 11 March 2011; through the courtesy of Fukushima Pref.) $)^{3)}$.

(WWII), was sandy soil including only a small fines content (Fig. 5a). This fact is consistent with the observation that the top fill was eroded very fast by the overtopping flow (Fig. 3). The degree of compaction (Fig. 6) was very low in the top fill: i.e., $\left(D_{\mathrm{c}}\right)_{4.5 \mathrm{Ec}}=84 \%$ and $\left(D_{\mathrm{c}}\right)_{1 \mathrm{Ec}}=87.9 \%$. With a similar soil type of the top fill in the old auxiliary dam, the 
a)

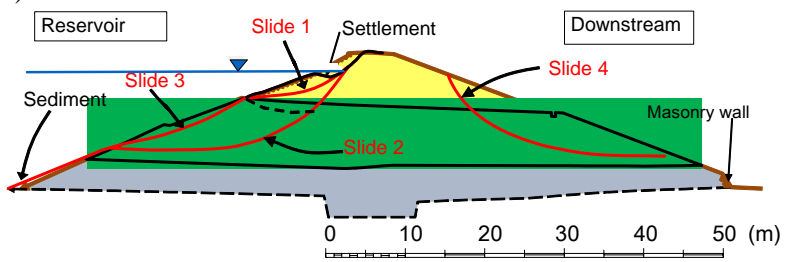

b)

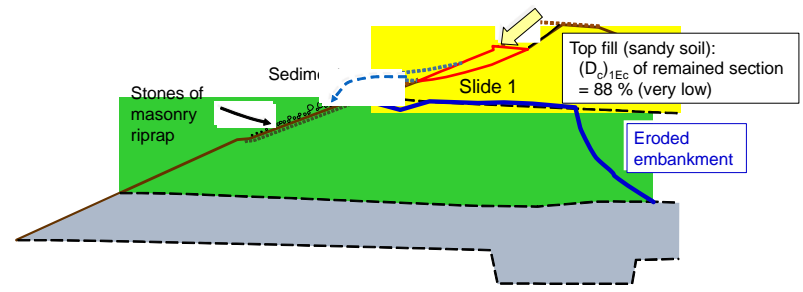

Fig. 4 Inferred failure mechanism of the old main Fujinuma $\mathrm{Dam}^{3)}$.

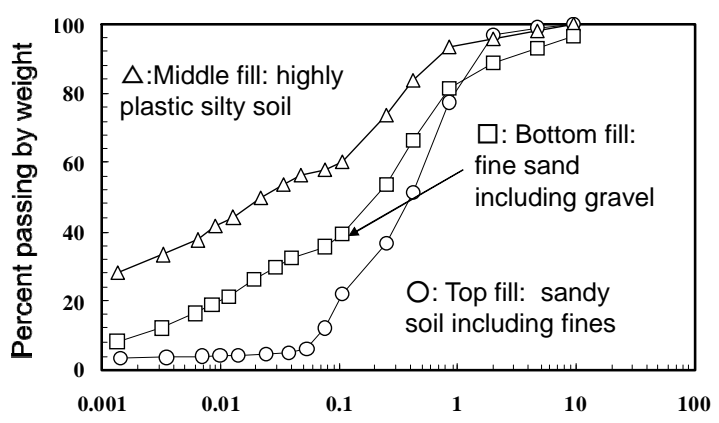

a)

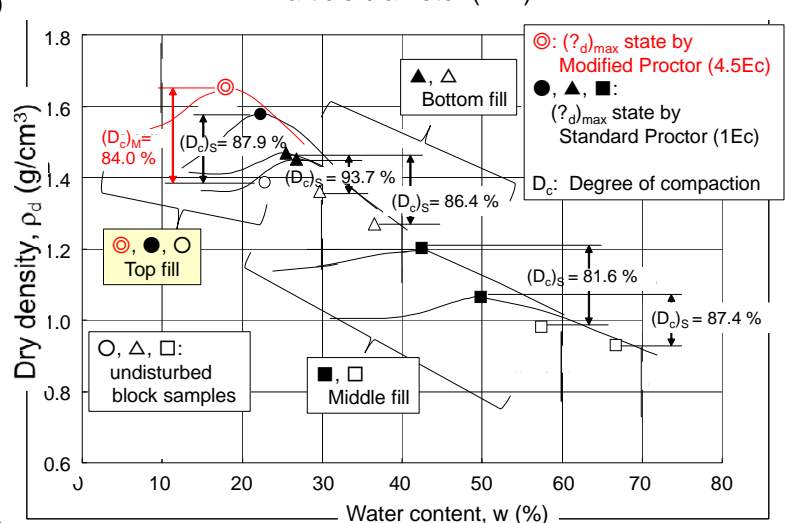

b)

Fig. 5 a) Grading curves of top, middle, and bottom fills of the old main dam; and b) compacted states of three fills near the right bank, old main Fujinuma dam³).

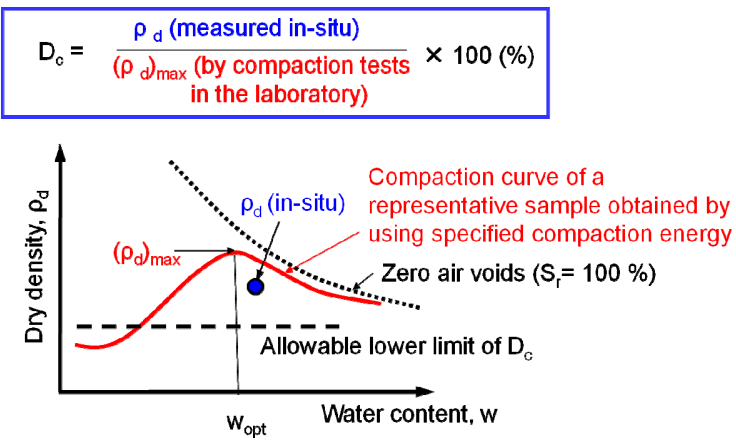

Fig. 6 Definition of the degree of compaction.
$\left(D_{\mathrm{C}}\right)_{1 \mathrm{Ec}}$ value was only $79.1 \%$ (Fig. 7c). These low $\left(D_{\mathrm{c}}\right)_{1 \mathrm{Ec}}$ values are due probably to too low compaction energy. On the other hand, an average $\left(D_{\mathrm{c}}\right)_{1 \mathrm{Ec}}$ in the order of $95 \%$ is usually achieved by modern earthwork performed to satisfy the allowable minimum value of $90 \%$, as specified in the old design code for agricultural irrigation dams ${ }^{4}$. As shown later, in the restoration work of this dam that followed the new design code revised in $2015^{5)}$, it is specified that all the measured values of $\left(D_{\mathrm{C}}\right)_{1 \mathrm{Ec}}$ should be equal to at least $95 \%$.

The middle fill, which was completed before a break during WWII, consists of highly plastic silty soil. This soil type is appropriate for achieving a low hydraulic conductivity and a high resistance against erosion that is necessary as the fill material for this type of earth-fill dam. This fact is consistent with the observation that the middle fill exhibited a relatively

a)

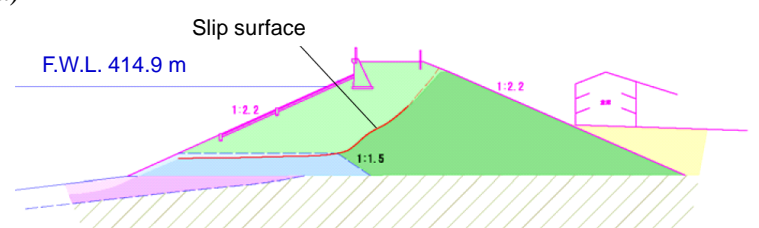

b)

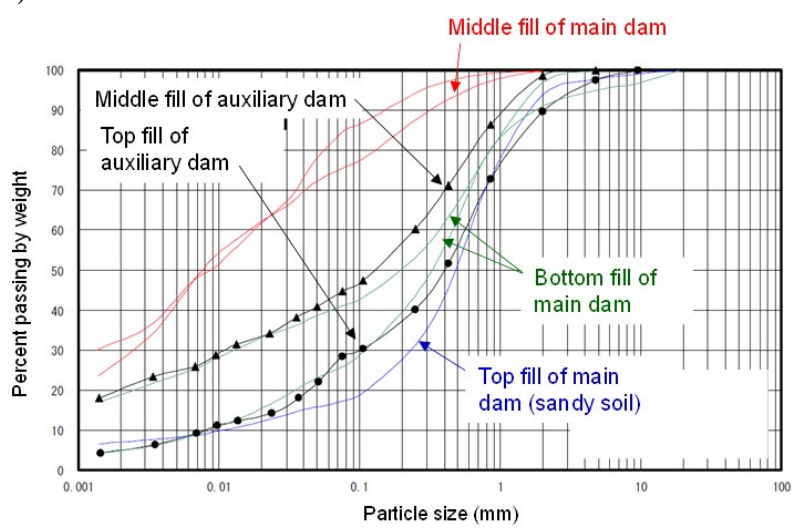

c)

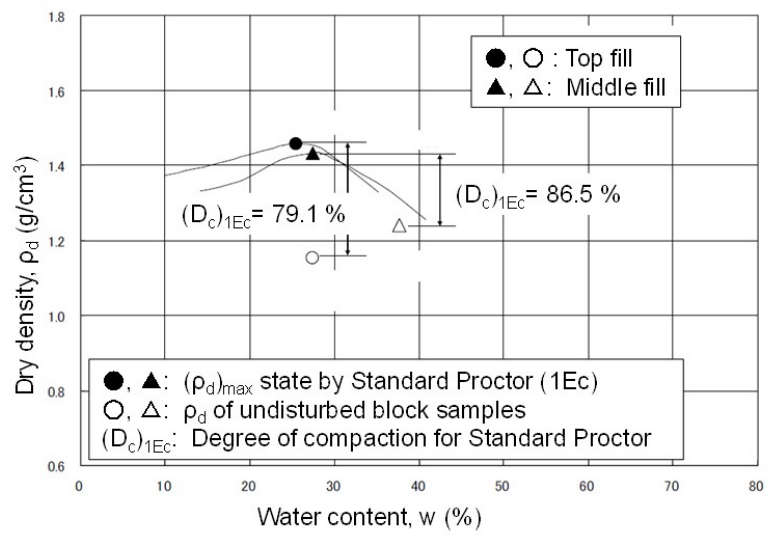

Fig. 7 a) Structure; b) grading curves; and c) compacted states of two fill types (at the central part), the old auxiliary $\mathrm{dam}^{3)}$. 
high resistance against erosion by the overtopping flow (Fig. 3). Yet, the measured values of $\left(D_{\mathrm{c}}\right)_{1 \mathrm{Ec}}$ of the middle fill are very low, not acceptable according to not only the new design code but also the old one. These low $\left(D_{\mathrm{c}}\right)_{1 \mathrm{Ec}}$ values are due probably to: a) the very low level of the compaction energy used and $b$ ) too high water content during compaction. The bottom fill was fine sand including gravel, which was compacted best among the three fills of the old main dam, despite being the earliest to be constructed. Yet, the compaction was not satisfactory based on the modern standard of earthwork.

Based on the above, the causes for the collapse of the old main dam were inferred as follows:

1) The compaction was generally poor with all of the top, middle, and bottom fills. This was due likely to lack of modern compaction control with too low compaction energy achievable at the time of compaction.

2) The soil type of the top fill was sandy soil, which was not the appropriate soil type, as it was highly liquefiable when loose and saturated; not sufficiently impermeable; and highly erodible.

At the time of the earthquake, the water level in the reservoir was highly prepared for the start of irrigating rice fields. Thus, the lower part of the top fill was under the phreatic surface.

3) The likely scenario of collapse is as follows:

a) In the saturated and nearly saturated zone in the top fill, the undrained shear strength dropped significantly from an initial value, which was not high, by cyclic undrained loading during the earthquake.

b) Failure started in the top fill (slide 1 in Figs. 4a and 4 b). Multiple slides 1 probably took place progressively.

c) Immediately after the start of event b), larger failure by slide 2 took place at the top and middle fills.

d) Events b) and c) resulted in the start of overtopping somewhere along the crest.

e) The scale of overtopping flow quickly became larger owing to the fast erosion of the top fill.

f) The breaching of the whole dam took place causing flooding of the entire amount of water impounded in the reservoir.

A slide occurred also in the old auxiliary dam, consisting of similar backfill materials as the old main dam (Figs. 7a and 7b). Unlike the old main dam, overtopping flow did not take place. It is not certain whether this fact means that the slide in the old auxiliary dam took place as a result of the fast drawdown in the reservoir as a result of the beaching of the old main dam. It is also possible that the slide took place owing to seismic loads during the earthquake when the reservoir was fully impounded causing the breach of the old main dam. This was because the slide was of the same flow type as the one that took place under water ${ }^{3)}$.

\section{DISCUSSION ON NEW POLICIES ON SEISMIC DESIGN OF IMPORTANT EARTH STRUCTURES}

\section{(1) Design and construction to satisfy required seismic performance}

When evaluating the seismic stability of earth structures, including earth-fill dams that are to be newly constructed or those currently existing in engineering practice, we often face problems resulting from an inconsistency between:

1) actual behavior reflecting actual soil stress-strain properties during an actual severe earthquake (or earthquakes); and

2) apparent behavior evaluated by the conventional seismic design method using assumed soil stress-strain properties for specified (or assumed) seismic load.

In Fig. 8a, these two behaviors are represented by two sets of a pair of points on the plane of soil shear strength, $\tau_{\mathrm{f}}$, and working shear stresses, $\tau_{\mathrm{w}}$. The safety factor, $F_{\mathrm{s}}$, is defined by the ratio $\tau_{\mathrm{f}} / \tau_{\mathrm{w}}$. If the point is located below the diagonal line of $F_{\mathrm{s}}=1.0, F_{\mathrm{s}}$ becomes lower than 1.0, thus the concerned earth structure collapses because of the given seismic load. If the point is located above the line of $F_{\mathrm{s}}=1.0, F_{\mathrm{s}}$ becomes higher than 1.0, thus the concerned earth structure does not collapse. In this Figure, letter A stands for an earth structure having well-compacted high-quality backfill with a high soil shear strength. It is herein considered that an actual earth structure A survives the actual severe seismic load defined as Level 2 seismic load (explained below). On the other hand, letter B stands for an earth structure having poorly compacted low-quality backfill with low soil shear strength. It is herein considered that earth structure B collapses by the actual Level 2 seismic load. In Fig. 8a, two values of $\tau_{\mathrm{w}}$ caused by the following two different levels of design seismic load according to Japanese Society for Civil Engineers $(1996)^{6}$ are indicated as follows:

1) Level 1 design seismic motion: It is a seismic motion with a high likelihood of occurring during the design lifetime of the concerned structure. It is required that, in principle, all new structures have sufficient seismic resistance to ensure "no damage" when subjected to this seismic motion.

2) Level 2 design seismic motion: It is the strongest seismic motion thought likely to occur at the location of the concerned structure in the future. It is required that the structure should not collapse, 
a)

Shear strength of fill, $\tau_{f}$

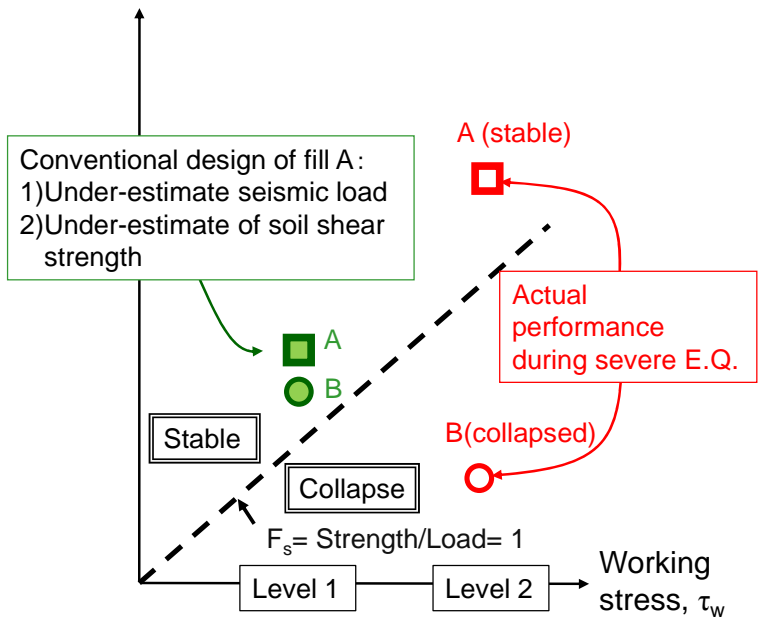

b)

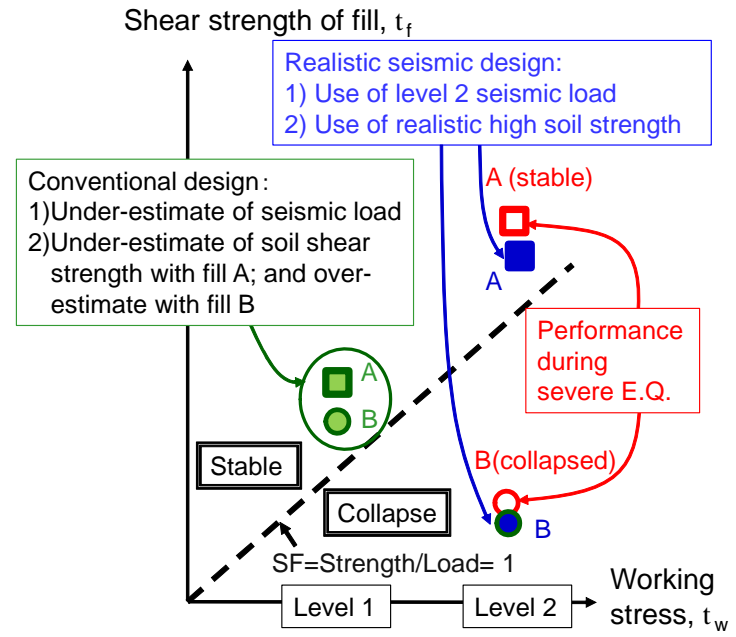

Fig. 8 Schematic diagrams comparing: a) actual performance of well- and poorly constructed earth structures and their conventional seismic designs; and b) actual performance of well- and poorly constructed earth structures, their conventional designs and their newly proposed seismic designs.

although damage that renders it unusable is acceptable if its functionality can be rapidly restored.

Since the experience of serious geo-hazards in the 1995 Hyogoken-Nanbu Earthquake and a number of subsequent seismic events, seismic design that takes into account Level 2 design seismic motion for earth structures and the foundations of superstructures has been gradually introduced, However, the timing of the change and the level of seismic resistance required are different among different types of earth structure and different organizations responsible for this issue. For example, with agricultural irrigation dams, the old code $^{4)}$ specified that the stability is evaluated by the pseudo-static limit equilibrium-based stability analysis on the following condi- tions:

1) the design value of horizontal seismic coefficient, $k_{\mathrm{h}}$, is equal to 0.15 , which is today considered as Level 1 design seismic load;

2) the design soil shear strength, $\left(\tau_{\mathrm{f}}\right)_{\mathrm{d}}$, is the drained shear strength when $\left(D_{\mathrm{c}}\right)_{1 \mathrm{Ec}}$ is equal to the allowable minimum value (e.g., 90\%) in compaction control; and

3) the required minimum factor of safety, $F_{s}$, is equal to 1.2 .

The design code for agriculture irrigation dams was revised in 2015 $5^{5}$. That is, with important irrigation dams of which collapse may result in a serious disaster, the new code requires the use of: 1 ) a relevant Level 2 design seismic motion; and 2), with saturated soil, undrained shear strength that may degrade by cyclic undrained loading. With respect to 1 ), $k_{\mathrm{h}}=0.15$ is too low to represent Level 2 design seismic load.

With well-compacted earth structure A, it is often used to conservatively determine the design shear strength, for example, based on underestimated degree of compaction per Standard Proctor $\left(D_{\mathrm{c}}\right)_{1 \mathrm{Ec}}$. Thus, the effects of an underestimation of seismic load and an underestimation of soil shear strength on the calculated value of $F_{\mathrm{s}}$ may be balanced, resulting in a relevant $F_{\mathrm{s}}$ value as illustrated in Fig. 8a. In this case, if only the design seismic load is levelled up under otherwise the same conditions, this balance is lost and the $F_{\mathrm{s}}$ value is underestimated, which usually happens in many cases of well-designed and constructed earth structures.

On the other hand, with poorly compacted earth structure B, typically Fujinuma dams that collapsed during the 2011 Off the Pacific Coast of Tohoku Earthquake (explained above), the effects of the following two factors are not balanced but are additive or synergistic:

1) The use of $k_{\mathrm{h}}=0.15$ as Level 2 design seismic load is on the unsafe side.

2) The use of the shear strength when the dry density is higher than the actual value as the design shear strength is on the unsafe side. Besides, if saturated poorly-compacted soil is sheared undrained during an earthquake, the use of drained shear strength as the design undrained shear strength is an additional factor on the unsafe side.

Due to these factors on the unsafe side, a largely unsafe design (i.e., a largely overestimated $F_{\mathrm{s}}$ value) is obtained. In this case, to obtain realistic results by the stability analysis, it is not sufficient to level up the design seismic load to Level 2, but it is also necessary to use realistic soil shear strength much lower than the conventional design value. With saturated poorly-compacted soil, the realistic undrained shear strength that has degraded owing to cyclic undrained 
loading during seismic loading is usually much lower than the corresponding drained shear strength.

Commonly with earth structures A and B, the relevant and realistic design should be based on the following procedures (Fig. 8b):

a) Level 2 design seismic load relevant to a given earth structure is used.

b) Realistic soil shear strength, $\tau_{\mathrm{f}}$, is used. With saturated soil, $\tau_{\mathrm{f}}$ could be either undrained or drained strength depending on the drain condition in the field. In the seismic design of a new earth structure, $\tau_{\mathrm{f}}$ corresponding to the target compacted value of $\left[D_{\mathrm{c}}\right]_{1 \mathrm{Ec}}$, which can be assumed to be equal to the anticipated average value, may be used as the design shear strength. This value is noticeably higher than a given allowable lower bound (e.g., 95\%). When evaluating the seismic stability of an existing earth structure, the average value of actual $\tau_{\mathrm{f}}$ should be evaluated to be used in the stability analysis.

c) The stability is evaluated by comparing the calculated residual displacement/deformation of a given earth structure with the allowable limit specified in design.

When based on this method, as illustrated in Fig. 8b, the stabilities of earth structures A and B become largely different, unlike in the conventional method following the conventional design code (e.g., the one for agricultural irrigation dams).

It was decided to restore the collapsed Fujinuma dams to make them much more stable, or be sufficiently stable against the severe seismic motion that caused the old dams to fully collapse. To satisfy this requirement, it became necessary to much better compact backfill materials of higher quality. To this end, a new soil compaction control method was developed, as described in the next section. Obviously, stability analysis based on the conventional method following the old design code is not able to show that the seismic stability of the new dams is substantially higher than those of the old dams. To this end, the seismic stability of the new dams was evaluated folowing the methods a), b), and c) described above, which can also explain the collapse of the old main dam.

\section{(2) Controlling water content, dry density, and degree of saturation for proper fill compac- tion}

The conventional fill compaction procedure usually controls the dry density, $\rho_{\mathrm{d}}$, and the water content, $w$, relative to the maximum dry density, $\left(\rho_{\mathrm{d}}\right)_{\max }$, and the optimum water content, $w_{\mathrm{opt}}$, determined by laboratory compaction tests performed at a certain compaction energy level (CEL) using a sample representative of concerned earthwork. However, $\left(\rho_{\mathrm{d}}\right)_{\max }$ increases and $w_{\text {opt }}$ decreases with an increase in CEL. Since Proctor ${ }^{7)}$, the maximum CEL practically achievable in the field has been increasing and the required $\rho_{\mathrm{d}}$ value has generally becoming higher for more satisfactory performance of earth structures. Besides, even when fixed soil type and CEL are specified, the soil type and CEL may vary in the field, thus the values of $\left(\rho_{\mathrm{d}}\right)_{\max }$ and $w_{\mathrm{opt}}$ inevitably change. In addition, it is very difficult to accurately estimate the field CEL and identify the actual soil type at a given moment at a given place. Therefore, the actual values of $\left(\rho_{\mathrm{d}}\right)_{\max }$ and $w_{\mathrm{opt}}$ at a given moment at a given place are usually unknown.

On the other hand, the following facts have been revealed by analysis of the results from a comprehensive series of laboratory and field compaction tests, CBR tests, laboratory stress-strain and permeability tests etc. of compacted soil as reported in details in Tatsuoka):

1) The optimum degree of saturation $\left(S_{\mathrm{r}}\right)_{\mathrm{opt}}$, defined as the degree of saturation, $S_{\mathrm{r}}$, where $\left(\rho_{\mathrm{d}}\right)_{\max }$ is obtained for a given CEL and a given soil type, and the relationship between the true degree of compaction $\left(D_{\mathrm{c}}\right)_{\mathrm{t}}=\rho_{\mathrm{d}} /\left(\rho_{\mathrm{d}}\right)_{\max }(\mathrm{x} 100 \%)$ and $S_{\mathrm{r}}$ $\left(S_{\mathrm{r}}\right)_{\text {opt }}$ obtained by compaction tests using a certain soil type at a certain CEL are essentially independent of CEL and insensitive to soil type variations.

2) The strength and stiffness before and after soaking, the hydraulic conductivity after saturation of compacted soil, and the collapse deformation upon wetting are a function of the dry density, $\rho_{\mathrm{d}}$, and " $S_{\mathrm{r}}$ at the end of compaction relative to the value of $\left(S_{\mathrm{r}}\right)_{\text {opt }}$ " (not a function of $\rho_{\mathrm{d}}$ and $w$ ) in addition to soil type in terms of particle size, grading, etc.

Despite inevitable unknown variation in the soil type and CEL, according to facts 1) and 2), the value of $\left(D_{\mathrm{c}}\right)_{\mathrm{t}}$ and the physical properties of compacted soil at a given moment at a given location can be estimated from measured values of $\rho_{\mathrm{d}}$ and $S_{\mathrm{r}}$ if the value of $\left(S_{\mathrm{r}}\right)_{\mathrm{opt}}$ and the $\left(D_{\mathrm{c}}\right)_{\mathrm{t}} \mathrm{vs} . S_{\mathrm{r}}-\left(S_{\mathrm{r}}\right)_{\mathrm{opt}}$ relation have been obtained by laboratory compaction tests on the representative sample using a certain CEL.

Based on the facts described above, Tatsuoka ${ }^{8)}$ and Tatsuoka and Gomes Correia ${ }^{9}$ proposed a compaction control method, which is more efficient than the conventional method. Importantly, this method does not contradict the conventional soil compaction control, but it unifies several approaches in the conventional practice, which are generally not well related to each other and/or apparently inconsistent with each other. The method consists of the following procedures:

a) The compaction targets of $S_{\mathrm{r}}$ and $\rho_{\mathrm{d}}$ (or $\left(D_{\mathrm{c}}\right)_{1 \mathrm{Ec}}$ for example) are determined by establishing a link between the soil compaction control and the de- 
a)

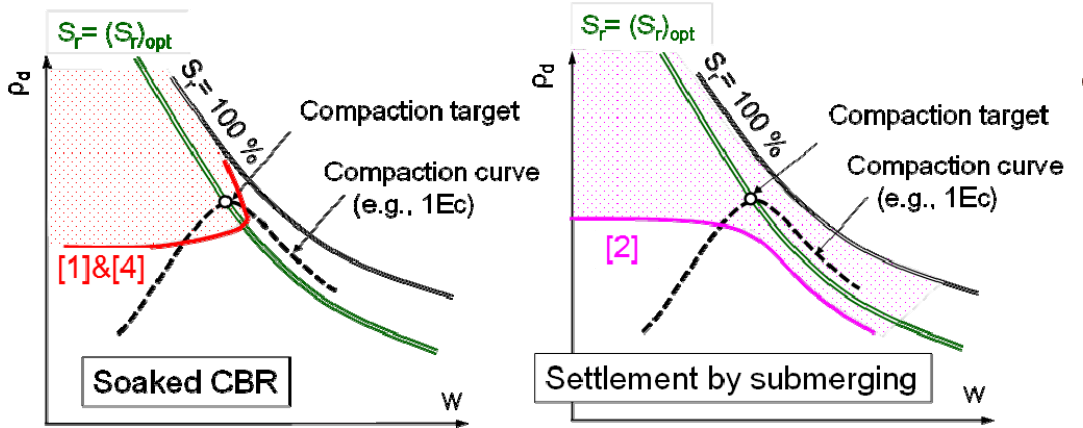

c)

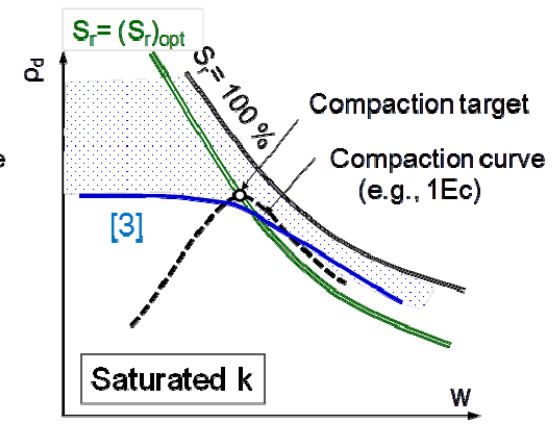

\begin{tabular}{|l|l|l|l|c|c|}
\hline \multicolumn{2}{|c|}{$\begin{array}{r}\text { Required properties } \\
\text { of compacted soil }\end{array}$} & $\begin{array}{l}\text { [1] High } \\
\text { strength \& } \\
\text { stiffness }\end{array}$ & $\begin{array}{l}\text { [2] Small collapse, } \\
\text { \& [2]' small } \\
\text { strength reduction } \\
\text { upon wetting }\end{array}$ & $\begin{array}{l}\text { [3] Low } \\
\text { permeability }\end{array}$ & $\begin{array}{l}\text { [4] No } \\
\text { danger of } \\
\text { over- } \\
\text { compaction }\end{array}$ \\
\hline \multirow{2}{*}{$\begin{array}{l}\text { For fill material to } \\
\text { be compacted }\end{array}$} & $\mathrm{WL}$ for $\mathrm{w}$ & Important $^{1)}$ & Essential & Important & \\
\cline { 2 - 6 } & $\mathrm{WU}$ for $\mathrm{w}$ & Essential $^{2)}$ & & & Essential \\
\cline { 2 - 6 } For compacted fill & $\mathrm{DL}$ for $\mathrm{D}_{\mathrm{c}}$ & Essential & Important & Important & Important \\
\cline { 2 - 6 } & $\mathrm{SL}$ for $\mathrm{S}_{\mathrm{r}}$ & & Essential & Essential & \\
\cline { 2 - 7 } & $\mathrm{SU}$ for $\mathrm{S}_{\mathrm{r}}$ & Important & & & Essential \\
\hline
\end{tabular}

Notes 1) \& 2): These control boundaries are either essential or important to achieve this soil property.

Fig. 9 a)-c) Contours of allowable bounds of three typical soil properties often required in design and the corresponding acceptable or allowable zones ${ }^{8), 9)}$.

sign of concerned earth structure. To this end, it is ensured that the $S_{\mathrm{r}}$ value of compacted soil is close to $\left(S_{\mathrm{r}}\right)_{\text {opt }}$ while $\rho_{\mathrm{d}}$ becomes higher than the target value, $\left(\rho_{\mathrm{d}}\right)_{\text {target }}$ that can realize the soil properties required in design. That is, as shown in Figs. 9a, 9b, and 9c, the value of $\left(\rho_{\mathrm{d}}\right)_{\text {target }}$ is determined so that the compaction target is located inside all of the acceptable zones, each of which is lower-bounded by the contour representing an allowable lower or upper limit value (i.e., a solid curve) for respective physical properties considered in design. The illustrations presented in these figures were constructed based on detailed analysis of a huge amount of data reported in Tatsuoka ${ }^{8)}$.

b) Not only $\rho_{\mathrm{d}}$ (or $\left(D_{\mathrm{c}}\right)_{1 \mathrm{Ec}}$ for example) and $S_{\mathrm{r}}$, but also $w$ are controlled in a unified manner. The control boundaries of $\rho_{\mathrm{d}}, S_{\mathrm{r}}$, and $w$ are specified to restrict the effects of their inevitable scatters. In Fig. 10a, the control boundaries are denoted by DL (i.e., lower bound for compacted dry density), WL, and WU (lower and upper bounds for water content) and SL and SU (lower and upper bounds for the degree of saturation). The purposes of setting these control boundaries are listed in the table inset in Fig. 9. They are related to each other in a consistent manner (Fig. 10a).

The results from laboratory compaction tests performed at a specified CEL are the bases for the proposed compaction control. However, the proposed method is applicable to other CEL values, while it is not

a)

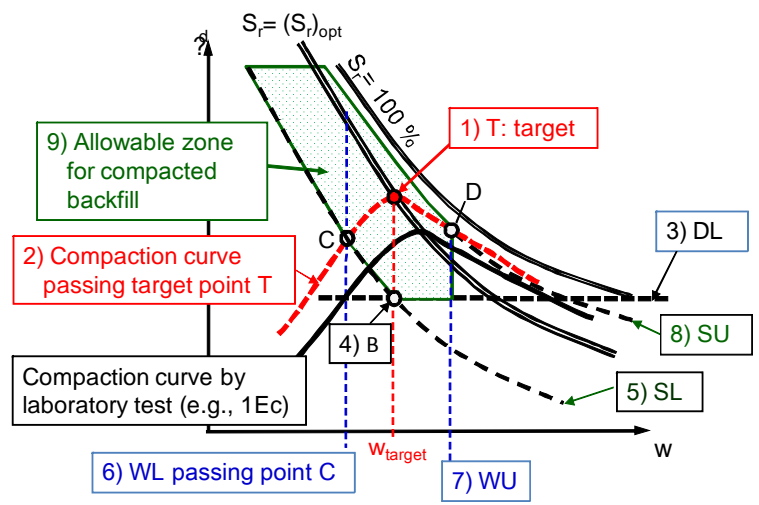

b)

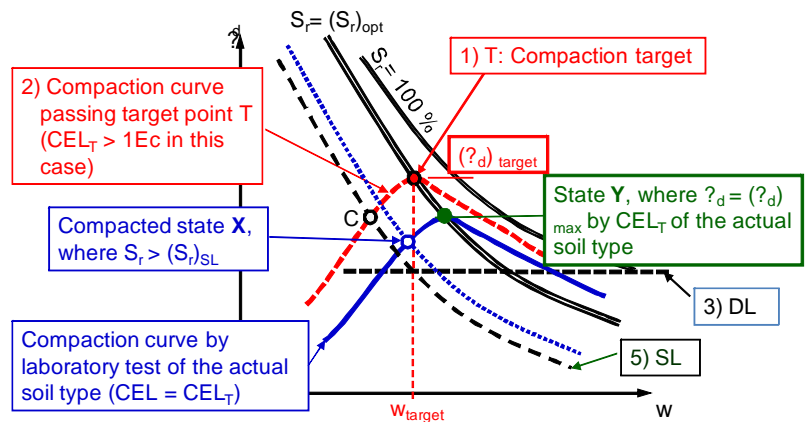

Fig. 10 a) Soil compaction control to achieve the soil properties required in design of a given earth structure; and b) the true degree of compaction $\left(D_{\mathrm{c}}\right)_{\mathrm{t}}$ when CEL is well controlled to be constant equal to $\mathrm{CEL}_{\mathrm{T}}{ }^{8), 9)}$.

required to evaluate the field CEL value, which is variable and very difficult to evaluate.

Figure 10a shows the overall picture of the soil 
compaction control procedure proposed based on the analysis shown above. This method comprises steps 1-9 explained below.

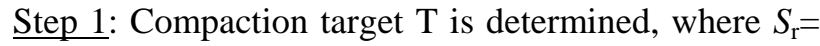
$\left(S_{\mathrm{r}}\right)_{\text {opt }}$ (irrespective of CEL and soil type variations in the field); and $\rho_{\mathrm{d}}=\left(\rho_{\mathrm{d}}\right)_{\text {target }}$ that can realize the required soil properties determined as shown in Fig. 9.

Step 2: The in-situ target compaction curve, which passes point $\mathrm{T}$, is obtained by assuming that "the $\rho_{\mathrm{d}} /\left(\rho_{\mathrm{d}}\right)_{\max }$ and $S_{\mathrm{r}}-\left(S_{\mathrm{r}}\right)_{\mathrm{opt}}$ curve” is not affected by variations in CEL.

Step 3: The allowable lower bound for $\rho_{\mathrm{d}}$, DL, is determined, where $D_{\mathrm{c}}=\rho_{\mathrm{d}} /\left(\rho_{\mathrm{d}}\right)_{\text {target }} \mathrm{X} 100 \%$ is equal to a specified value, such as $95 \%$. Several sets of data as the rationales for $95 \%$ are reported in Tatsuoka $(2015)^{8)}$.

Step 4: Point B where $w=$ "the value at target T, $w_{\text {target }}$ " is obtained along DL.

Step 5: The constant $S_{\mathrm{r}}$ curve that passes point B is defined as the allowable lower bound for $S_{\mathrm{r}}$, SL. SL crosses the target compaction curve at point $\mathrm{C}$. If the allowable lower bound of $S_{\mathrm{r}}$ is specified to satisfy requirements for hydraulic conductivity, for example, and if this $S_{\mathrm{r}}$ value is higher than the value at point B, the $S_{\mathrm{r}}$ value for SL (i.e., the $S_{\mathrm{r}}$ value at point C) is reset to be equal to that $S_{\mathrm{r}}$ value.

Step 6: The allowable lower bound for $w, \mathrm{WL}$, is specified to pass point C: i.e., $w_{\mathrm{WL}}=$ " $w$ at point C."

Step 7: The allowable upper bound for $w$, WU, where $w=w_{\mathrm{WU}}=w_{\text {target }}+x$, is specified to avoid too low strength/stiffness and to prevent overcompaction. Trial field compaction tests may be necessary to obtain the reliable value of $x$ in respective projects. Only the fill material having $w$ between $w_{\mathrm{WL}}$ and $w_{\text {WU }}$ is allowed to be compacted.

Step 8: The allowable upper bound for $S_{\mathrm{r}}$, SU, is specified to pass point $\mathrm{D}$, where $\mathrm{WU}$ crosses the target compaction curve. Alternatively, the allowable upper bound for $S_{\mathrm{r}}$, SU, is first specified as $\left(S_{\mathrm{r}}\right)_{\mathrm{opt}}+5 \%$, for example, then point D is obtained where SU crosses the target compaction curve. Then, WU is obtained to pass point D.

Step 9: The allowable or acceptable zone for compacted soil comprising boundaries SL, DL, WU, and SU is specified. Basically, WL is not necessary to define this zone. This is because compacted soils with $w<$ $w_{\mathrm{WL}}$ can satisfy the required soil proprieties if the compacted state is located in this allowable zone. In actuality, if $w<w_{\mathrm{WL}}$, it is very difficult to reach this allowable zone even by compaction using a very high CEL. Thus, compaction using backfill having $w$ $<w_{\mathrm{WL}}$ is not allowed. On the other hand, if the compacted fill is required to be homogeneous to prevent differential deformation, the left part of the allowable zone may be truncated by $\mathrm{WL}$, and/or an upper bound for $\rho_{\mathrm{d}}$, DU, may be additionally specified.

According to this proposed method, even if the water

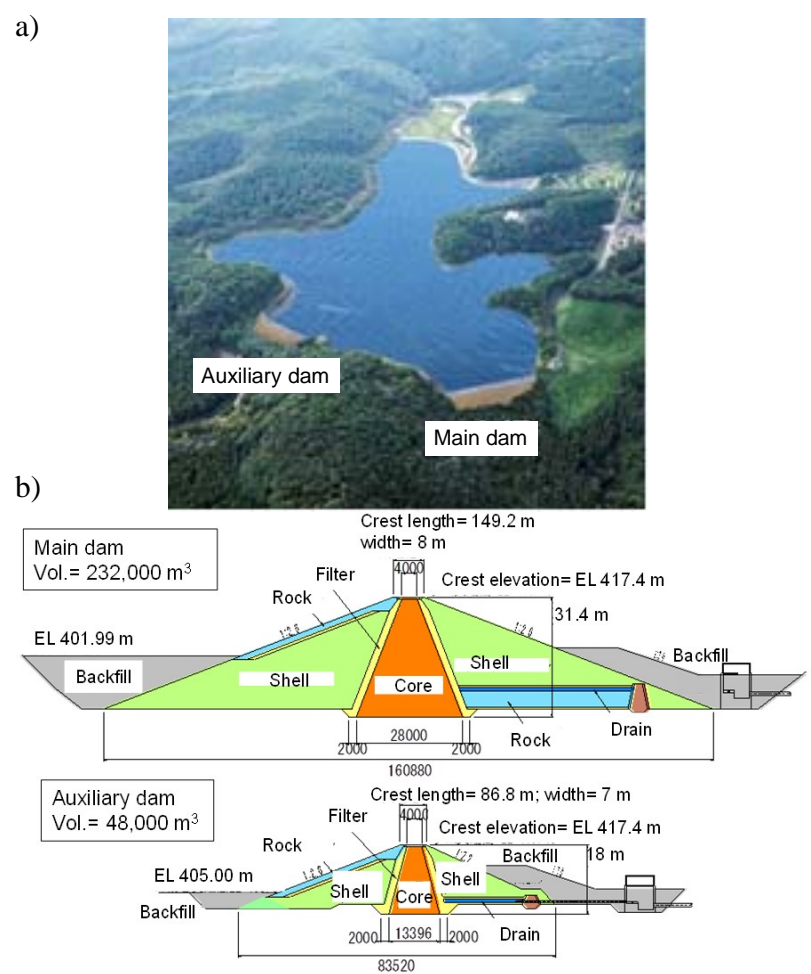

Fig. 11 a) Artist's view; and b) typical cross-section of the restored main and auxiliary Fujinuma dams ${ }^{12), 13)}$.

content is lower than $w_{\text {target }}$, compacted states become acceptable when $\left(D_{\mathrm{c}}\right)_{1 \mathrm{Ec}}$ is equal to, or higher than, the specified allowable lower band while $S_{\mathrm{r}}$ is in between the allowable lower and upper bounds. Thus, this method encourages compaction to higher dry densities by using higher CELs at water contents lower than the optimum water content defined for CEL lower than field CEL. In the earthwork to restore the Fujinuma dams, the compaction control was and is being performed basically following this proposed method.

\section{RESTORATION WORK ON FUJINUMA DAMS}

The new Fujinuma dams (Fig. 11) were designed to be much more stable than the old ones based on stability analysis evaluating residual displacement/deformation when subjected to the seismic load by which the old dams collapsed ${ }^{10)}$. This seismic load was considered as Level 2 seismic load for these dams. The analysis was performed based on the slip displacement evaluated by the Newmark method taking into account the deterioration of undrained shear strength by preceding cyclic undrained loading during a given seismic load and the residual deformation excluding components due to slip displacement evaluated by the pseudo-static non-linear FEM analysis ${ }^{11)}$.

At the design stage, to determine the details of field compaction method, a series of field full-scale compaction tests was performed using the planned 
a)

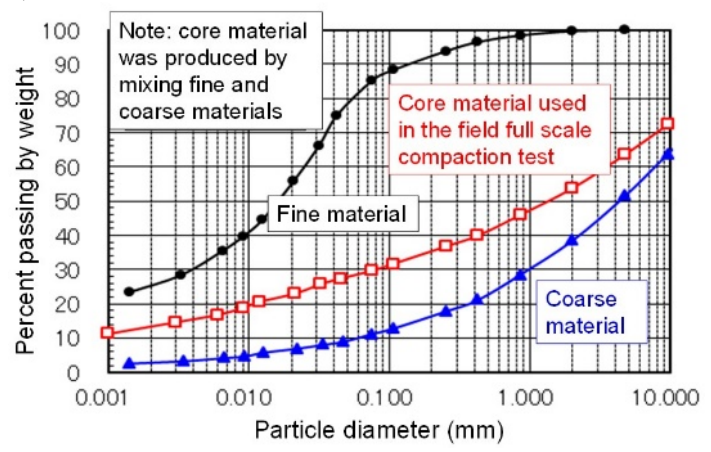

c)

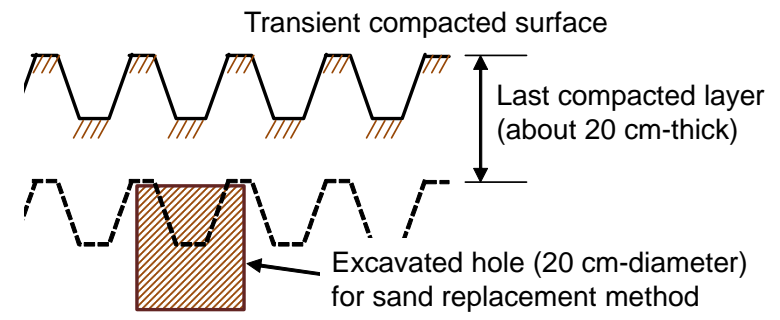

b)

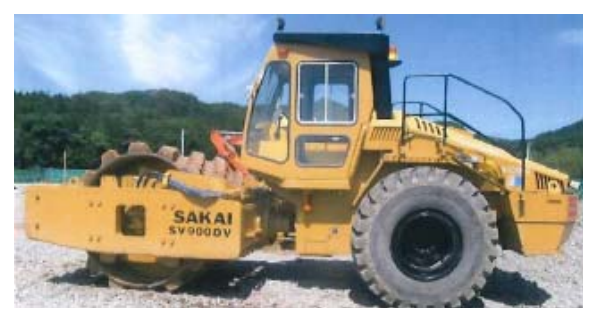

d)

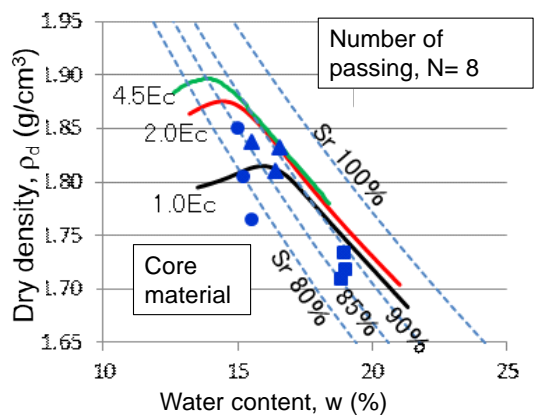

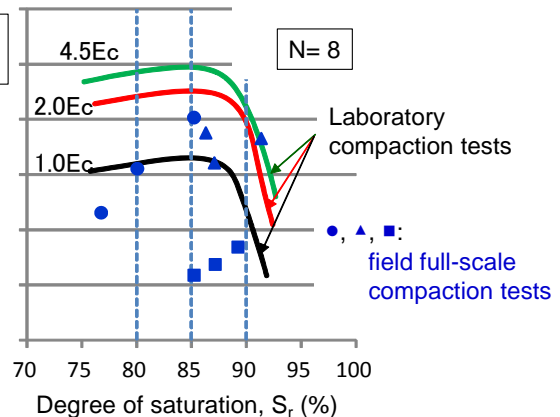

Fig. 12 Field full-scale compaction test of core material for Fujinuma dams: a) grading curve of core material; b) 20 ton-class vibratory tamping roller; c) measuring method of the field $\rho_{\mathrm{d}}$ and $w$ values; and d) results of compaction at three different $w$ values ${ }^{12), 13)}$.

core material (Fig. 12a). A compaction machine shown in Fig. 12b was used. The following three different water contents were chosen to find the relevant water content for actual field compaction works: $w=\left(w_{\mathrm{opt}}\right)_{1 \mathrm{Ec}} ; w=\left(w_{\mathrm{opt}}\right)_{1 \mathrm{Ec}}-1.5 \%$; and $w=$ $\left(w_{\mathrm{opt}}\right)_{1 \mathrm{Ec}}+4.0 \%$. The field dry density and water content were measured in the soil layer immediately underlying the transient top soil layer (Fig. 12c). When compacted at $w=18.9 \%=\left(w_{\mathrm{opt}}\right)_{1 \mathrm{Ec}}+2.4 \%$, the $\rho_{\mathrm{d}}$ value did not increase with an increase in the number of passing of the compaction machine $(N)$ and, as seen from Fig. 12d, the ultimate $\rho_{d}$ value never reached the value corresponding to the compaction curve obtained by laboratory compaction tests using compaction energy of 1Ec: i.e., overcompaction took place. On the other hand, when $w=15.3 \%=\left(w_{\mathrm{opt}}\right)_{1 \mathrm{Ec}}-1.2 \%$ and $16.5 \%=\left(w_{\mathrm{opt}}\right)_{1 \mathrm{Ec}}$, most of the $\rho_{\mathrm{d}}$ values after $N=8$ became slightly larger than $\left(\rho_{\mathrm{d}}\right)_{\max .1 \mathrm{Ec}}$. Based on the above and to ensure sufficiently low hydraulic conductivity, the compaction target for the core material was determined such that $\left(S_{\mathrm{r}}\right)_{\text {target }}=\left(S_{\mathrm{r}}\right)_{\text {opt }} ; w_{\text {target }}=\left(w_{\mathrm{opt}}\right)_{1 \mathrm{Ec}}$ $+0.5 \%$; and $\left(\rho_{\mathrm{d}}\right)_{\text {target }}=$ " $\rho_{\mathrm{d}}$ when $w=\left(w_{\mathrm{opt}}\right)_{1 \mathrm{Ec}}+0.5 \%$." This $\left(\rho_{\mathrm{d}}\right)_{\text {target }}$ value was nearly the same as $\left(\rho_{\mathrm{d}}\right)_{\max .1 \mathrm{Ec} \cdot}$. In addition, the control boundaries (Fig. 9) were determined such that: a) the allowable lower bound of $\left(D_{\mathrm{c}}\right)_{1 \mathrm{Ec}}$ was equal to $95 \%$; b) the allowable lower and upper bounds of $S_{\mathrm{r}}$ are $\left(S_{\mathrm{r}}\right)_{\mathrm{opt}}-5 \%$ and $\left(S_{\mathrm{r}}\right)_{\mathrm{opt}}+$ $5 \%$; and c) the allowable lower and upper bounds of the water content, $w$, of the backfill to be compacted are $\left(w_{\mathrm{opt}}\right)_{1 \mathrm{Ec}}-1.0 \%$ and $\left(w_{\mathrm{opt}}\right)_{1 \mathrm{Ec}}+2.0 \%$.

Figure 13a shows the grading curves of the core materials tested in the laboratory for field compaction control and those of the materials actually used to construct the core zone of the new auxiliary dam. Figure 13b shows the distribution of compacted states in the actually constructed core zone together with the acceptable zone specified in advance. It may be seen that the compaction was performed satisfactorily.

The field CEL was strictly controlled to be as constant as possible by monitoring using GPS installed in all the compaction machines. Therefore, a noticeable scatter seen in the data presented in Fig. 13c is due mainly to such a scatter in the grading characteristics among the backfill materails as seen from Fig. 13a. It is to be noted that, referring to Fig. 10b, if the CEL is kept to a certain constant value, $\mathrm{CEL}_{\mathrm{T}}$, and if $S_{\mathrm{r}}$ is maintained within the allowable upper and lower bounds, the scatter of the true degree of compaction, $\left(D_{\mathrm{c}}\right)_{\mathrm{t}}$ for $\mathrm{CEL}_{\mathrm{T}}$, is much smaller than the one of the values of apparent $D_{\mathrm{c}}$ values seen in Fig. 13b.

Figure 14a shows the grading curves of the shell materials tested in the laboratory and those of the materials actually used to construct the shell zone of the new auxiliary dam. With the shell material, the compaction target was determined such that $\left(S_{\mathrm{r}}\right)_{\text {target }}=$ $\left(S_{\mathrm{r}}\right)_{\mathrm{opt}} ; w_{\text {target }}=\left(w_{\mathrm{opt}}\right)_{1 \mathrm{Ec}} ;$ and $\left(\rho_{\mathrm{d}}\right)_{\text {target }}=\left(\rho_{\mathrm{d}}\right)_{\text {max.1Ec }}$. The control boundaries (Fig. 9) were determined such that: a) the allowable lower bound of $\left(D_{\mathrm{c}}\right)_{1 \mathrm{Ec}}$ was equal to $95 \%$; b) the allowable lower and upper bounds of $S_{\mathrm{r}}$ are $\left(S_{\mathrm{r}}\right)_{\mathrm{opt}}-15 \%$ and $\left(S_{\mathrm{r}}\right)_{\mathrm{opt}}+6 \%$; and c) the allowable 
a)

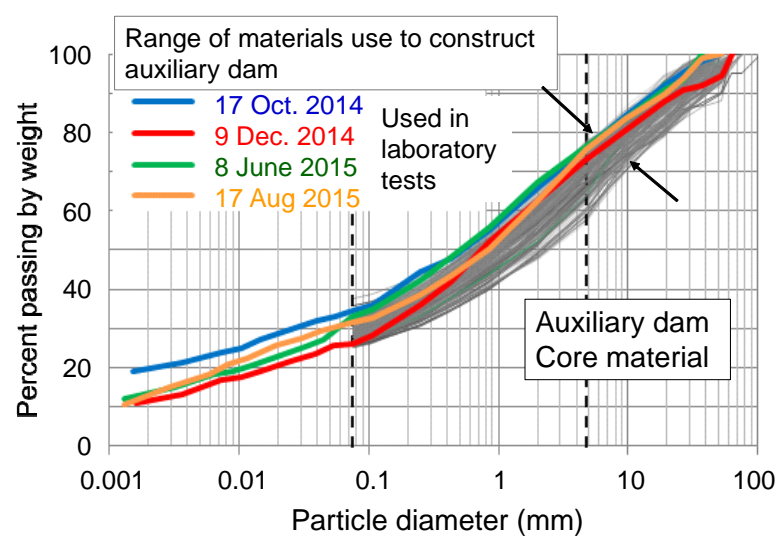

b)
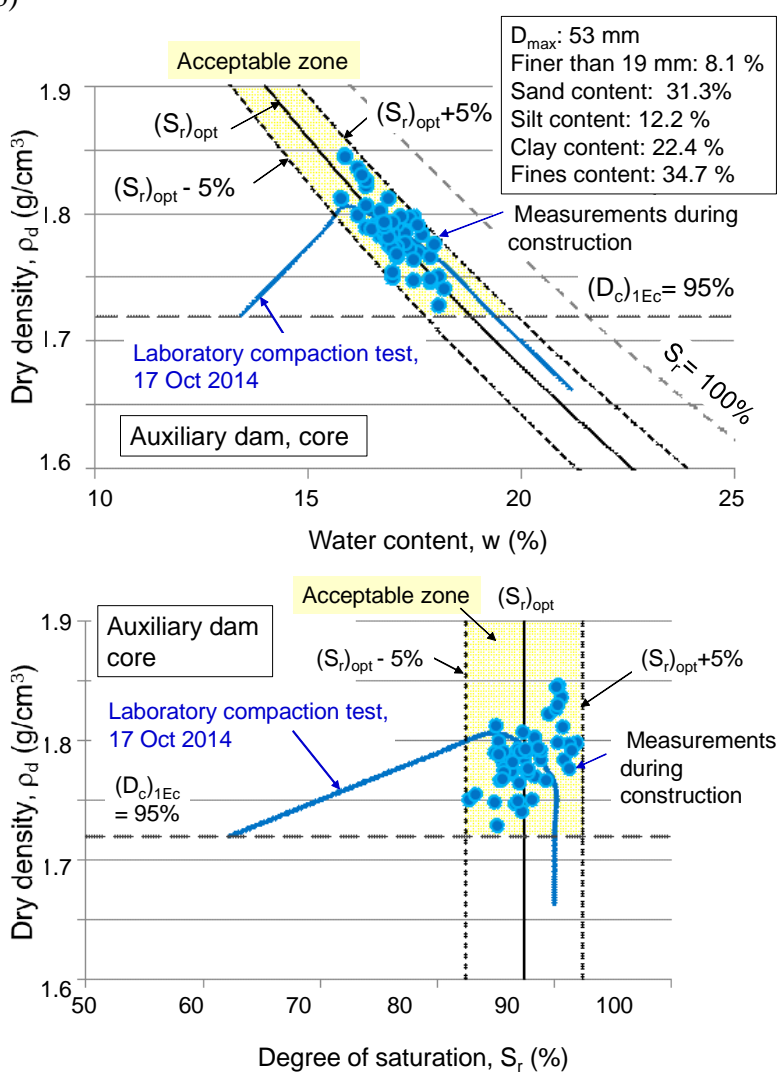

Fig. 13 Compaction control in the construction of the core of Fujinuma auxiliary dam: a) grading curves of core materials tested in the laboratory and those used to construct the core; b) results of compaction after a number of passing equal to $8^{12), 13)}$.

lower and upper bounds of $w$ for the backfill to be compacted are $\left(w_{\mathrm{opt}}\right)_{1 \mathrm{Ec}}-1.5 \%$ and $\left(w_{\mathrm{opt}}\right)_{1 \mathrm{Ec}}+1.0 \%$. The acceptable zone consisting of these boundaries is presented in Fig. 14b. Figure 14b shows the distribution of compacted states in the actually constructed shell zone. Despite a limited amount of data available at the time of writing this paper (August 2016), the data indicate that so far the soil compaction had performed satisfactorily.

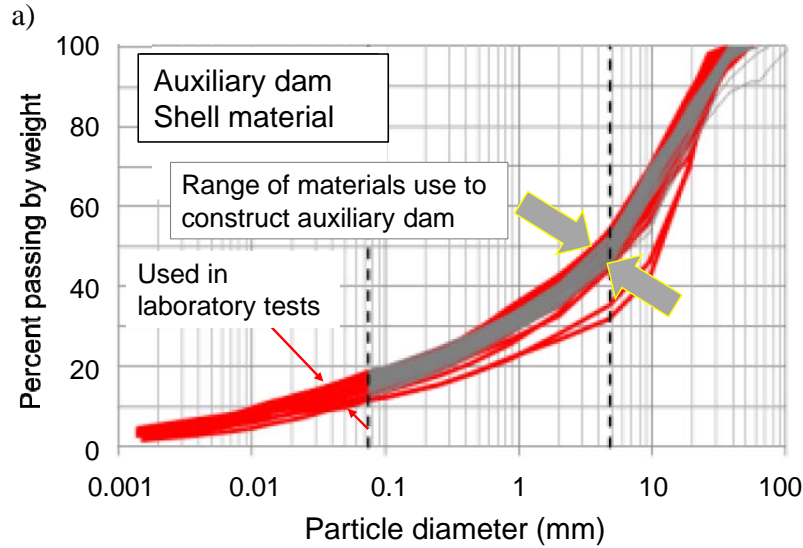

b)
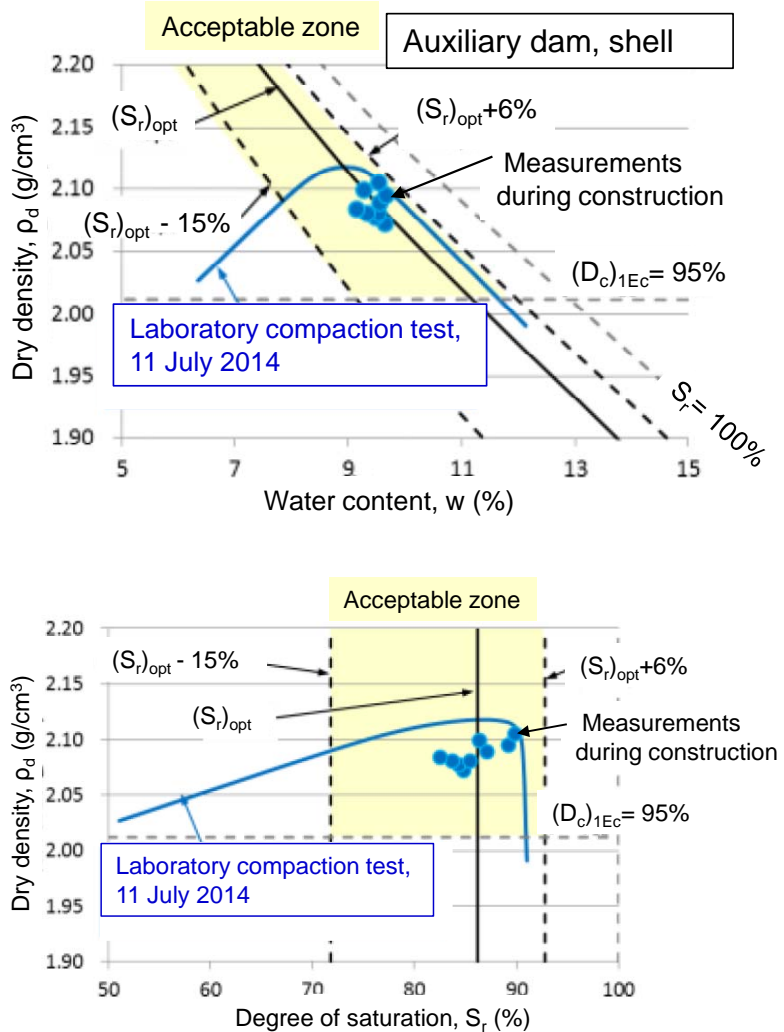

Fig. 14 Compaction control in the construction of the shell of Fujinuma auxiliary dam: a) grading curves of core materials tested in the laboratory and those used to construct the shell; b) results of compaction ${ }^{12), 13)}$.

\section{CONCLUSIONS}

As a typical and illustrative case study from which we can learn important lessons about the seismic design of earth structures, the collapse of the main and auxiliary Fujinuma dams owing to the 2011 Off the Pacific Coast of Tohoku Earthquake in Japan has been reported here. These dams are now being restored to become much more stable (as of September 2016). They will be completed by April 2017. De- 
signing and constructing the earth structures in order to satisfy the required seismic performance were also discussed. The following conclusions were obtained:

The soil types and compacted dry densities of the collapsed two dams inferred from the measurements in limited zones that survived the earthquake showed that: a) the compacted state was generally poor; and b) the top fill consisted of particularly poorly compacted sandy soil, which would have resulted in a significant reduction of undrained strength by cyclic undrained loading and a fast erosion by overtopping flow.

Based on the lessons learned, a proposal is made to revise the design policy for earth structures to be newly constructed, particularly in terms of compaction control and seismic design. With the latter term, the relevant and realistic design should be based on the following procedures: a) Level 2 design seismic load relevant to a given earth structure should be used; b) realistic soil shear strength, corresponding to the target value of the degree of compaction specified in soil compaction control, which can be assumed to be equal to the average of actual values and is usually noticeably higher than a given allowable lower bound (e.g. 95\%), should be used; and c) the stability should be evaluated by comparing the calculated residual displacement/deformation of a given earth structure with the allowable limit specified in design.

The results of the compaction control at the early stage of the restoration work for the new Fujinuma dams show that the newly proposed method that controls the water content of the backfill to be compacted and the dry density and the degree of saturation of compacted soil works very well to efficiently achieve high dry density states realizing high shear strength, low hydraulic conductivity and small collapse, and small strength reduction upon wetting.

ACKNOWLEDGMENTS: The authors express their sincere thanks to the members of the JGS Research Committee on aseismic measures for earth structures, which provided them with relevant information on earthquake-induced damage to earth structures and their design policy. In particular, the significant contribution of Dr. Kenichi Matsushima in reviewing the seismic design policy of earth-fill dams for irrigation reservoir in Japan is deeply acknowledged.

\section{REFERENCES}

1) Joint Editorial Committee for the Report on the Great East Japan Earthquake Disaster: Report on the Great East Japan
Earthquake Disaster -Geohazard 1, Damage and Restoration of Geotechnical Structures, Japanese Geotechnical Society (ed.), 2015 (in Japanese).

2) Japanese Geotechnical Society: Committee report - Research Committee on aseismic measures for earth structures-, Proc. of JGS Special Symposium -beyond the East Japan Great Earthquake Disaster-, pp.21-32, 2014. (in Japanese)

3) Tanaka, T., Tatsuoka, F. and Mohri, Y.: Earthquake-induced Failure of Fujinuma Dam, Proc. Int. Symp. on Dams for a Changing World, Kyoto, June 5, Vol. 6, pp. 47-52, 2012.

4) Ministry of Agriculture, Forestry and Fisheries: Planning and design criteria of land improvement project "earth dam,” Design code, February 2006. (in Japanese)

5) Ministry of Agriculture, Forestry and Fisheries: Planning and design criteria of land improvement project "earth dam,” Design code, May 2015 (in Japanese).

6) Japanese Society for Civil Engineers: Second recommendations about the seismic design standards for civil engineering structures, 10 January 1996 (in Japanese).

7) Proctor, R. R.: Fundamental principles of soil compaction, Engineering News-Record, New York, Vol.111, No.9, August 31, pp.55-58, 1933.

8) Tatsuoka, F.: Compaction characteristics and physical properties of compacted soil controlled by the degree of saturation, Deformation Characteristics of Geomaterials, V. A. Rinaldi et al. (eds.), IOS Press, pp.40-76, 2015.

9) Tatsuoka, F. and Gomes Correia, A.: Importance of controlling the degree of saturation in soil compaction, Proc. of the $3^{r d}$ International Conference on Transportation Geotechnics (ICTG 2016), Elsevier, pp.556-565, 2016.

10) Tatsuoka, F., Tanaka, T., Ueno, K., Duttine, A. and Mohri, Y.: Soil properties and seismic stability of old and new Fujinuma dams, Proc. International Symposium on Qualification of Dynamic Analyses of Dams and Their Equipment and of Probabilistic Assessment of Seismic Hazard in Europe, 31th August $-2^{\text {nd }}$ September, Saint-Malo, France (eds. Fry, J.-J. and Matsumoto, N.), 2016.

11) Duttine, A., Tatsuoka, F., Shinbo, T. and Mohri, Y. : A new simplified seismic stability analysis taking into account degradation of soil undrained stress - strain properties and effects of compaction, Proc. International Symposium on Qualification of Dynamic Analyses of Dams and Their Equipment and of Probabilistic Assessment of Seismic Hazard in Europe, 31th August $-2^{\text {nd }}$ September, Saint-Malo, France (eds. Fry, J.-J. and Matsumoto, N.), 2016.

12) Santanbata, I., Nagai, H., Yamagishi, A., Tatsuoka, F., Nakayama, M., Miura, T. and Watanabe, H.: Control of the degree of compaction in construction of Fujinuma Dam (No. 1: Outline of the embankment management), Proc. 51th Japan National Conference on Geotechnical Engineering, Paper No. 599, pp.999-1000, 2016 (in Japanese).

13) Nagai, H., Santanbata, I., Yamagishi, A., Tatsuoka, F., Nakayama, M., Miura, T. and Watanabe, H.: Control of the degree of compaction in construction of Fujinuma Dam (No. 1: results), Proc. 51th Japan National Conference on Geotechnical Engineering, Paper No. 600, pp.1001-1002, 2016 (in Japanese).

(Received October 6, 2016) 